\title{
Design and Analysis of the Eddy Current Brake with the Winding Change
}

\author{
Sooyoung Cho ${ }^{1}$, Huai-Cong Liu ${ }^{1}$, Ju Lee ${ }^{1}$, Chang-Moo Lee ${ }^{2}$, Sung-Chul Go ${ }^{3}$, \\ Sang-Hwan Ham ${ }^{4}$, Jong-Hyuk Woo ${ }^{1}$, and Hyung-Woo Lee ${ }^{5 *}$ \\ ${ }^{1}$ Department of Electrical Engineering, Hanyang University, Seoul, 04763, Republic of Korea \\ ${ }^{2}$ Korea Railroad Research Institute, Uiwang 16105, Republic of Korea \\ ${ }^{3}$ Samsung Electronics Company, Ltd., Suwon, Gyeongi-do, 16677, Republic of Korea \\ ${ }^{4}$ School of Electrical Engineering, Kyungil University, Gyeongsan, 38428, Republic of Korea \\ ${ }^{5}$ Department of Railway Vehicle System Engineering, Korea National University of Transportation, Uiwang, 16106, Republic of Korea
}

(Received 24 January 2017, Received in final form 16 February 2017, Accepted 21 February 2017)

\begin{abstract}
This paper is a study of the eddy current brake designed to replace the air brake of railway application. The eddy current brake has the advantage of being able to take a high current density compared to the other application because this brake is used for applying brakes to the rolling stock for a shorter amount of time. Also, this braking system has the merit of being able to take a high current density at low speed rather than at high speed, because the heat generated by the low speed operation is less than that of the high speed operation. This paper also presents a method of improving the output torque of the eddy current brake at low speed operation through a change of the winding as well as the basic design.
\end{abstract}

Keywords : eddy current brake, electric retarder, eddy current, winding change, auxiliary brake

\section{Introduction}

These days, a braking system of the rolling stock uses a mix the regenerative brake from induction motors and air brake from air pressure. The regenerative brake is the braking force that is primarily used, which produces a constant braking force at the previous area of the base speed. However, the regenerative brake becomes disadvantageous when the speed increases from the base speed due to the braking force reduction. Therefore, the air brake is used as the auxiliary brake to assist the required braking force. This brake is not driven before the base speed because of insufficient braking force, however, the braking force of this brake is increased when the speed increases after the base speed.

The air brake system has a few disadvantages in that it occupies large space, requires high maintenance costs, has slow braking response and a non-uniformity in the braking pressure, and has a change in the frictional force of the friction surfaces. Also, tread brake and disk brake exert a mechanical braking force using the air pressure, which

(C)The Korean Magnetics Society. All rights reserved.

*Corresponding author: Tel: +82-70-8855-1652

Fax:+82-70-8855-1652, e-mail: krhwlee@ut.ac.kr causes noise and particulate problems due to the use of friction materials such as brake shoes [1].

On the other hand, the eddy current brake belonging to the electrical retarder has fast braking responses and low maintenance costs. Also, this brake solves the noise problem because it is contactless. Due to this advantage, the ICE3 in Deutsche Bahn (DB) and Shinkansen in Japan are equipped with an eddy current brake at the rail sector. In the automotive sector, many company such as Industrial brake \& Friction supply Co. and SIGRA Co. in

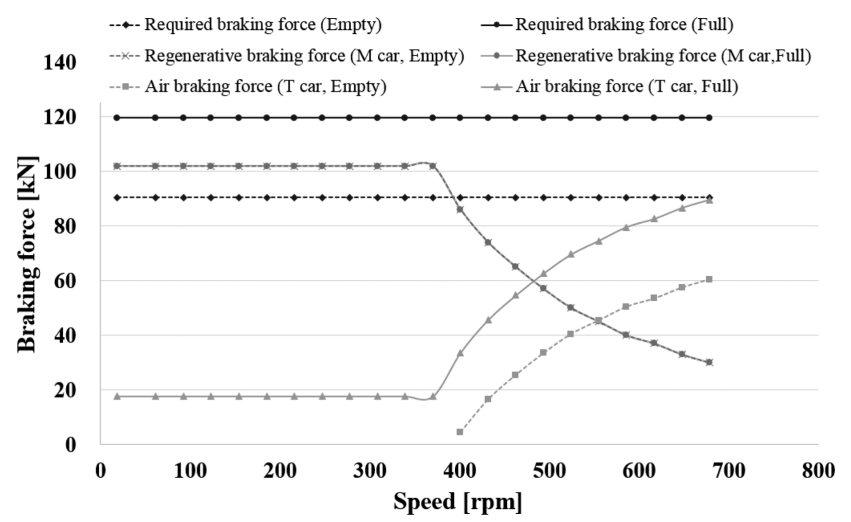

Fig. 1. Division of braking force of $\mathrm{M} / \mathrm{T}$ car in case of empty and full. 
Australia, Telma Co. and Voith Co. in Germany, CAMA Co. and Auhui Pioneering Electromagnetic Clutches Co. in China, Jacobs Co. in England and so on are investigating eddy current brakes for vehicle applications [2].

The eddy current brake presented in this paper is designed to reduce eddy current brake model of the drum type [3-6] because air gap length can be reduced to the drum type model rather than linear eddy current brake model $[7,8]$. Generally, the reduced air gap length can improve the output torque. Also, this model considers the maximum speed of the rolling stock. This paper lastly suggests the final eddy current brake design through the winding change by considering heat generation at various speeds.

\section{Principle of the Eddy Current Brake}

The electrical eddy current brake is composed of a fixed electromagnet and a conductive disk to rotate. If conductive disk rotates with a constant speed between the fixed electromagnet, an electromotive force is formed in accordance with formula (1) and the eddy current is generated. Then the conductive disc is stopped, which is under the force in a direction opposite to the rotational direction of a conductive disk according to Fleming's lefthand rule.

$$
e=-N \frac{d \phi}{d t}
$$

Also, it can be seen that the conductivity is also important in designing the eddy current brake because the eddy current is proportional to the eddy current conductivity, as shown in equation (2).

$$
\vec{J}=\sigma \vec{E}
$$

The maximum torque of the eddy current brake below.

$$
T_{m}=\frac{K_{m}}{\pi} \frac{1}{\mu_{o}}\left(\pi R^{2} L\right) B_{0}^{2}
$$

where $K_{m}$ is a numerical factor related to the relative permeability, $R$ is the radius of the rotor, $L$ is the length of laminate, and $B_{0}$ is an airgap magnetic flux density. That is, the maximum torque is proportional to the volume of the rotor and the square of the airgap magnetic flux density. Also, it related to the permeability, but it can be seen that it is associated the resistance component [9].

\section{Design of the Reduced Eddy Current Brake}

The basic model of the eddy current brake is shown in Fig. 2 and specification of the model is shown in

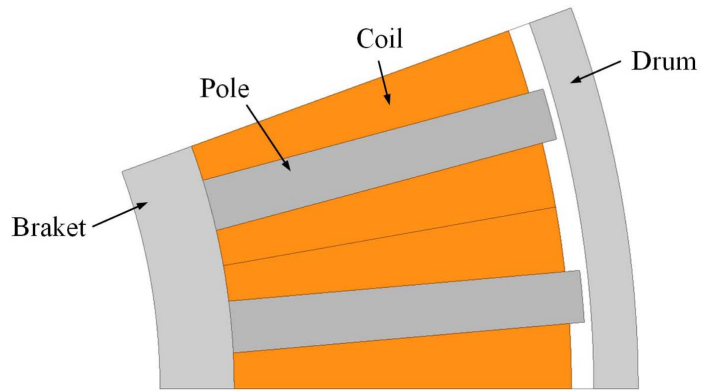

Fig. 2. (Color online) Basic model of the eddy current brake.

Table 1. Specification of the basic model at $700 \mathrm{rpm}$.

\begin{tabular}{ccc}
\hline \hline Contents & Value & Unit \\
\hline External diameter of drum \& braket & $300 \& 191$ & $\mathrm{~mm}$ \\
Width of Pole & 7 & $\mathrm{~mm}$ \\
Number of slots \& poles & $36 \& 18$ & - \\
Number of parallel circuits & 1 & - \\
Input current & 4.8 & $\mathrm{~A}$ \\
Number of turns & 243 & Turn \\
Torque & -62.44 & $\mathrm{Nm}$ \\
\hline
\end{tabular}

Table 1.

\subsection{Effect of the external diameter of the braket and width of the pole}

Based on the basic model, if this model changes the size of the external diameter of the braket and width of the pole, while the input current and width of the braket is fixed, the model changes the slot area, number of turns, and reluctance.

$$
\Re=\frac{l_{\text {Pole }}}{\mu_{r} \mu_{0} W_{\text {Pole }} N_{\text {Pole }} L_{\text {shafi }}}[A T / W b]
$$

where $W_{\text {Pole }}$ is the width of the pole, $N_{\text {Pole }}$ is the number of poles, $L_{s t k}$ is the length of laminate, and $l_{\text {Pole }}$ is the

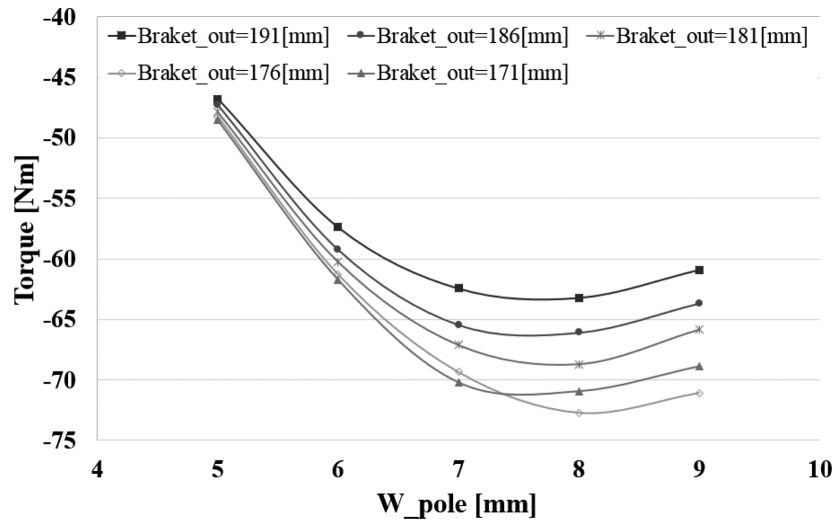

Fig. 3. Braking force according to the change in the external diameter of the braket and width of the pole at $700 \mathrm{rpm}$. 


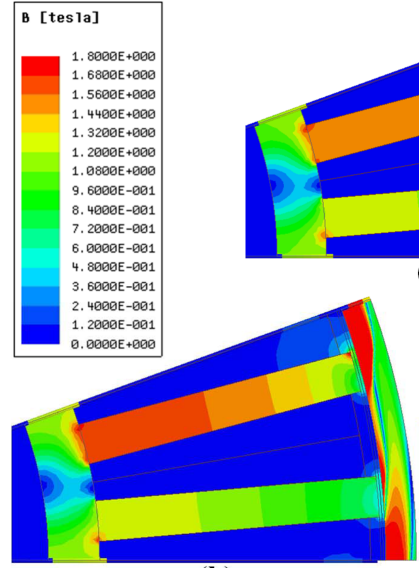

(b)

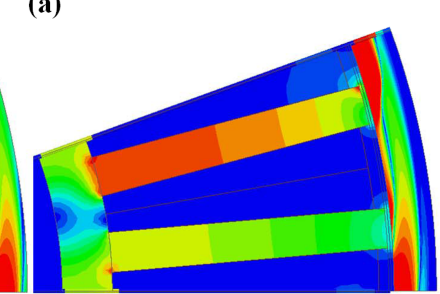

(c)
Fig. 4. (Color online) Effect of the width of the drum; External diameter of drum (a) $295 \mathrm{~mm}(\mathrm{~T}=-41.29 \mathrm{Nm})$ (b) 300 $\mathrm{mm}(\mathrm{T}=-70.55 \mathrm{Nm})(\mathrm{c}) 305 \mathrm{~mm}(\mathrm{~T}=-70.48 \mathrm{Nm})$.

\section{length of pole.}

In other words, the size changes at the magnetic saturation point and causes the optimum point of the torque according to Ohm's law.

Accordingly, the torque value obtained through the FEA at the maximum operating speed of $700 \mathrm{rpm}$ is shown in Fig. 3. Through Fig. 3, the maximum braking torque can be observed by reducing the external diameter of the braket and increasing the pole width of the original model.

\subsection{Effect of the width of the drum}

In order to examine the effect on the width of the drum, the magnetic flux density value is observed as shown in Fig. 4. The figure indicates that if the width of the drum reaches some extent, it does not contribute to the increase of torque.

\subsection{Optimization of the width and length of the shoe}

The shoe of the eddy current brake is presented to improve the output power, as shown in Fig. 5, and optimi-

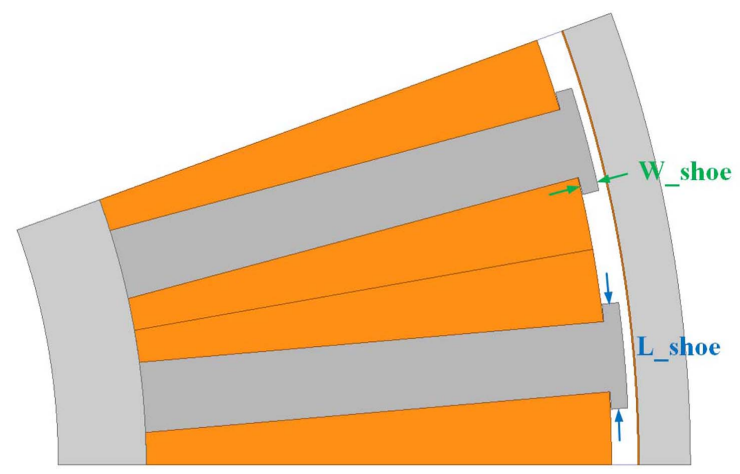

Fig. 5. (Color online) The width and length of the shoe.

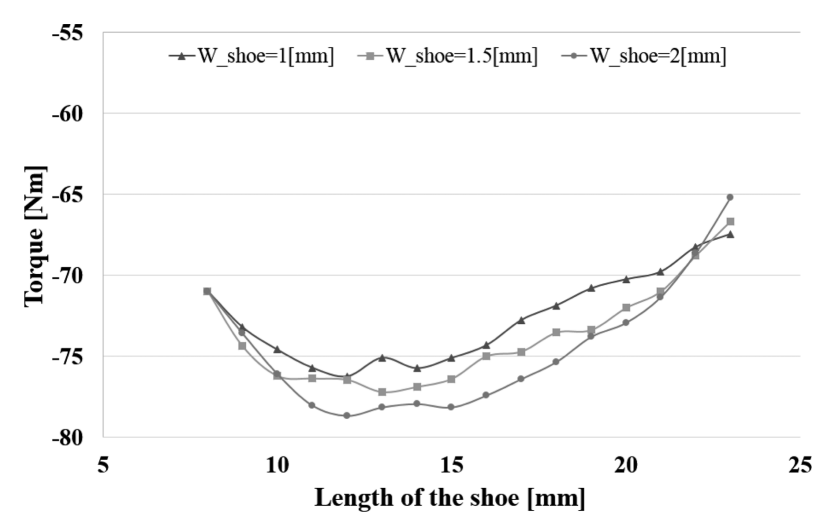

Fig. 6. Effect of the width and length of the shoe at $700 \mathrm{rpm}$.

zation of the shoe is shown in Fig. 6.

Based on the improved model, the shoe is formed so that the magnetic flux can flow better between the stator and the drum as shown in Fig. 6.

Due to the presence of the shoe, the output torque is increased. However, it can be observed that it is not ideal to increase the shoe size to a certain value because the magnetic flux path becomes longer than necessary, causing a leakage in the shoe edge.

\subsection{Effect and optimization of the copper coating}

In order to further increase the eddy current generated in the drum, a copper coating can be added on the internal diameter, which has an influence on the output torque because conductivity is proportional to the eddy current. However, if the internal diameter of the drum is slightly reduced and then the copper coating is added on the surface of the internal diameter of the drum, then this causes an additional air gap of as much as copper coating thickness. In the process, if the reluctance is largely increased compared to the amount of the increased flux, it is possible to reduce the output torque. As a result, torque is the largest at $0.15[\mathrm{~mm}]$ thickness of the copper coating and if the copper coating thickness becomes more than $0.7[\mathrm{~mm}]$, the output torque is reduced compared to the

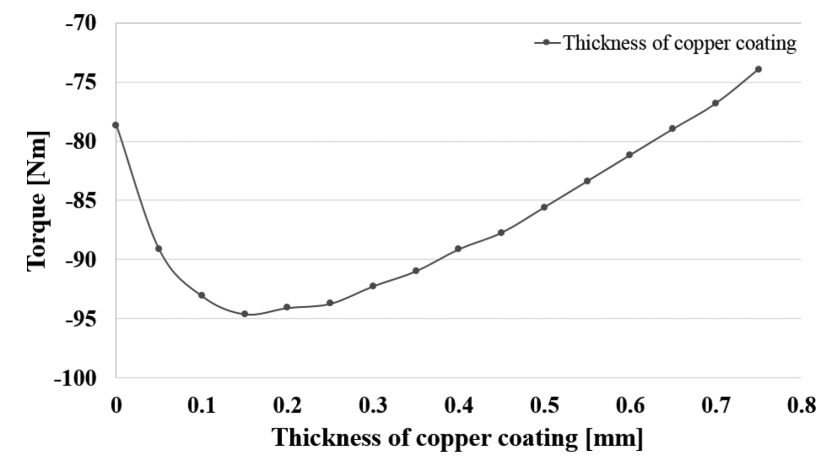

Fig. 7. Effect of the thickness of copper coating. 
original model, shown in Fig. 7.

\section{Final Model of the Eddy Current Brake}

Through these process, the final model of the eddy current brake is shown in Fig. 8 and specification of the model is shown in Table 2.

Table 2. Specification of the final model at $700 \mathrm{rpm}$.

\begin{tabular}{ccc}
\hline \hline Contents & Value & Unit \\
\hline External diameter of drum \& braket & $300 \& 176$ & $\mathrm{~mm}$ \\
Width of Pole & 8 & $\mathrm{~mm}$ \\
Length \& Width of Shoe & $12 \& 2$ & $\mathrm{~mm}$ \\
Number of slots \& poles & $36 \& 18$ & - \\
Number of parallel circuits & 1 & - \\
Input voltage & 171 & $\mathrm{~V}$ \\
Input current & 4.8 & $\mathrm{~A}$ \\
Current density & 9.55 & $\mathrm{~A} / \mathrm{mm}^{2}$ \\
Number of turns & 249 & $\mathrm{Turn}$ \\
Torque & -94.53 & $\mathrm{Nm}$ \\
\hline
\end{tabular}

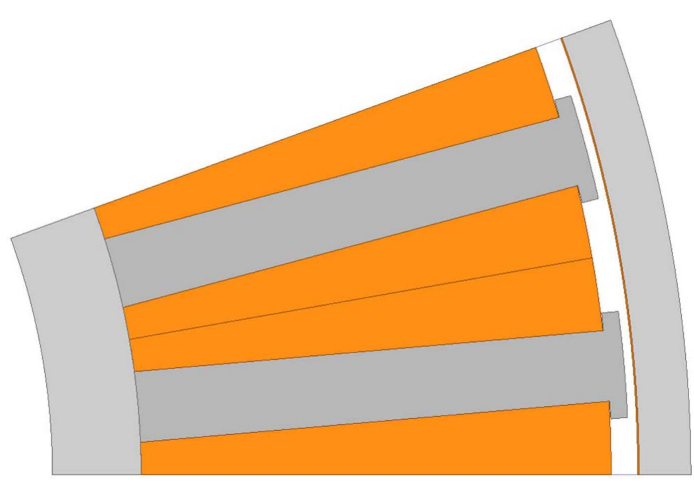

Fig. 8. (Color online) Final model of the eddy current brake.
4.1. Torque change according to the number of parallel circuits

The electrical eddy current brake can take a high current density of the coil contributing to the torque increase as the electric machine is driven for a short time of 10 to 15 seconds at the time of braking of the vehicle. Accordingly, if the parallel circuit in the voltage supply source system is increased, the current density is increased, and then it can contribute to the torque increase.

The winding change circuit for parallel circuit change is shown in Fig. 9. If the switches 1, 2, and 3 are turned on, the parallel circuit is set to 1 , and if the switches $1,3,4$, and 5 are turned on, the parallel circuit is set to 2 . Also when switches $2,6,7,8,9$ are turned on, the parallel circuit becomes 3 .

Using the final model and winding change circuit, the output torque according to parallel circuits and speeds is shown in Fig. 10.

In Fig. 10, the output torque is increased at the time of the increase in the parallel circuit, because increased current density contributes to increasing the output torque.

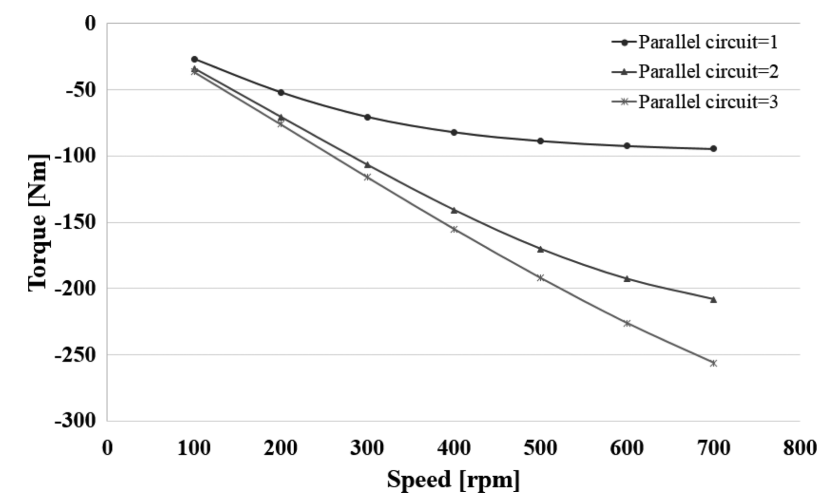

Fig. 10. Torque change according to the number of parallel circuits.

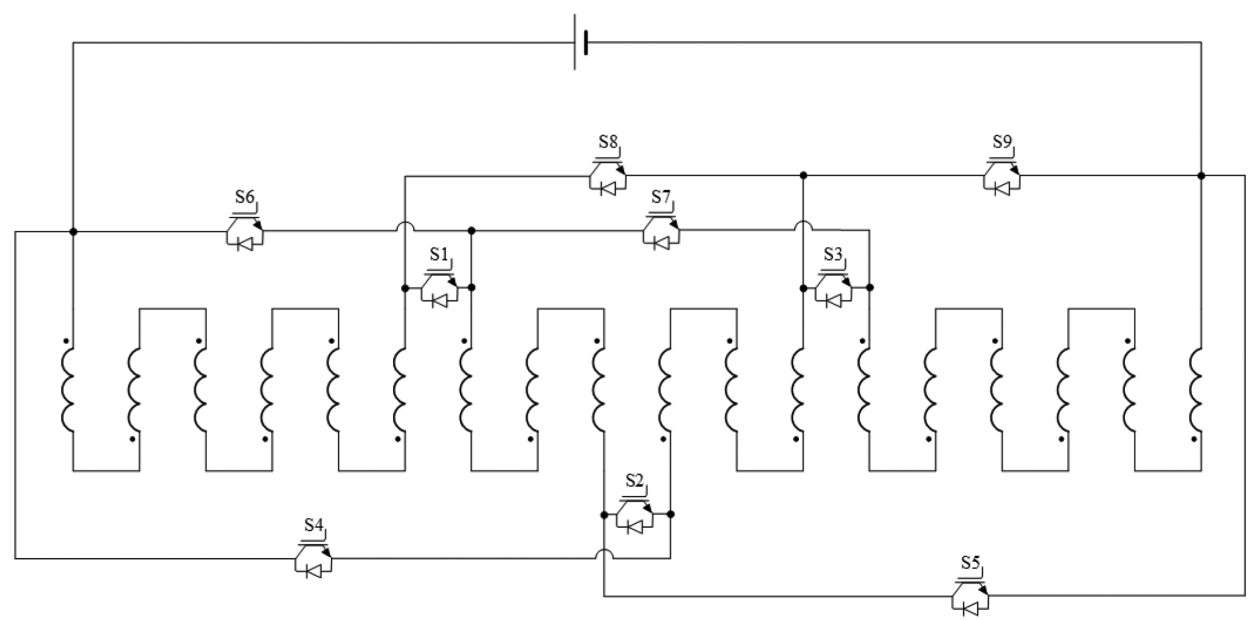

Fig. 9. Winding change circuit. 


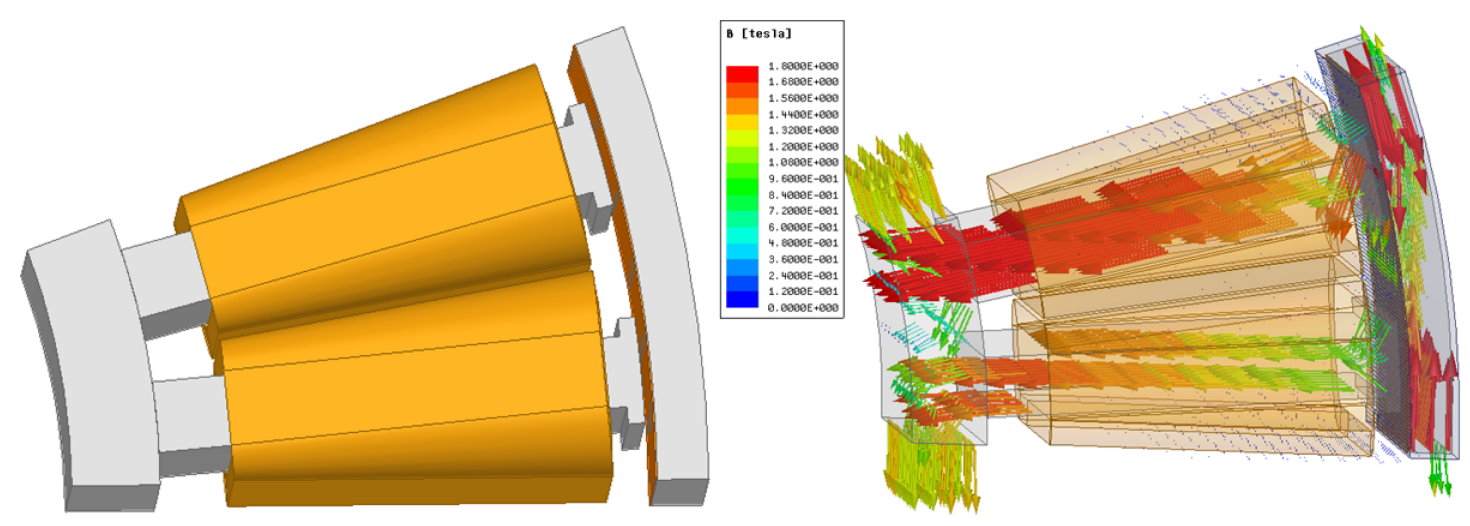

Fig. 11. (Color online) 3D model of the eddy current brake.

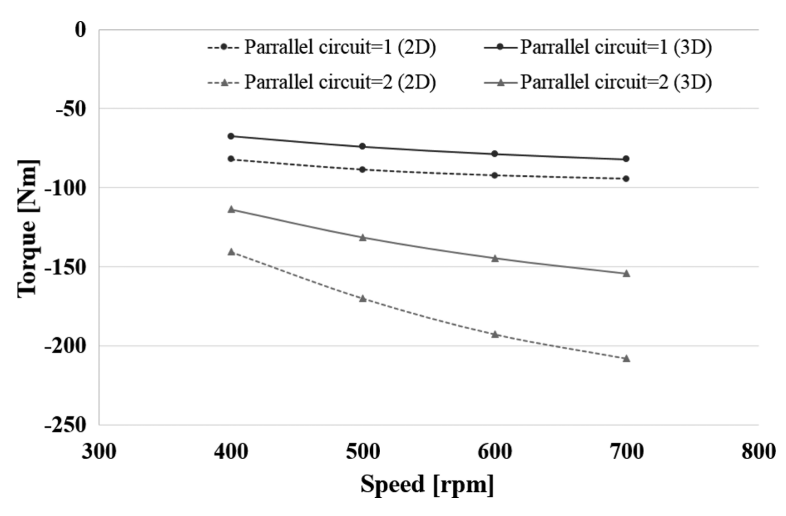

Fig. 12. Comparison analysis of the $2 \mathrm{D}$ and $3 \mathrm{D}$ model.

The eddy current brake is a short drive during braking and the heat generated by the low speed operation is less than the high speed operation. Therefore, if the parallel circuit is changed, the torque can be improved.

\subsection{Analysis of the $2 D$ and $3 D$ model}

The above analysis model is a 3D model of the eddy current brake. Also, the following is an analysis result of the $2 \mathrm{D}$ and $3 \mathrm{D}$ of the final model. The errors occurred because of generation of the difference of the eddy

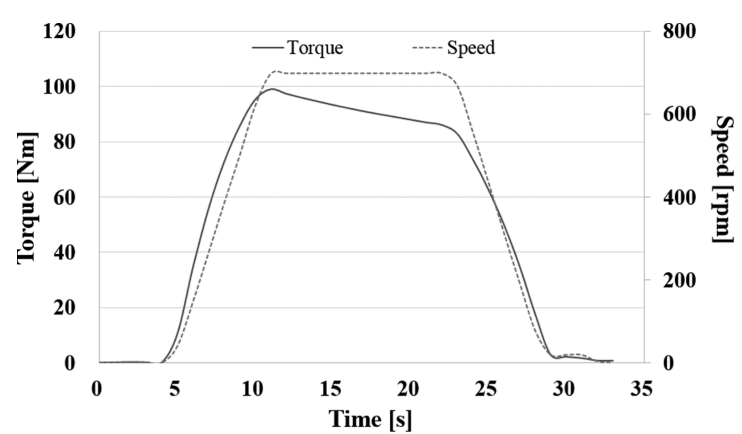

(a)

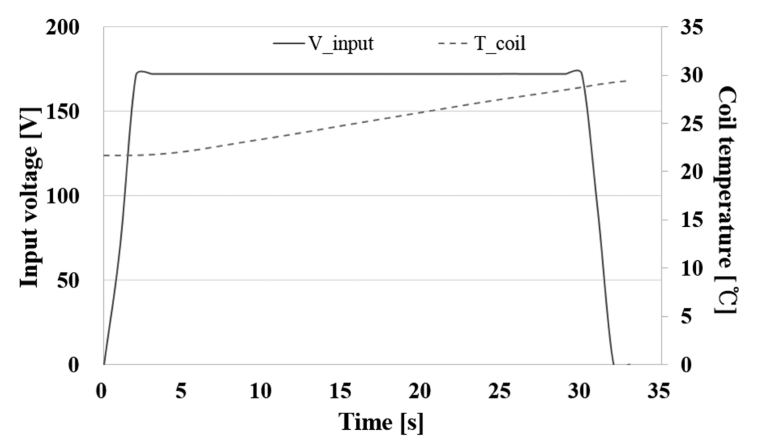

(b)

Fig. 14. (a) Torque and speed according to the time, (b) Input voltage and temperature of the coil at $700 \mathrm{rpm}$ and the number of the parallel circuit configured as one.
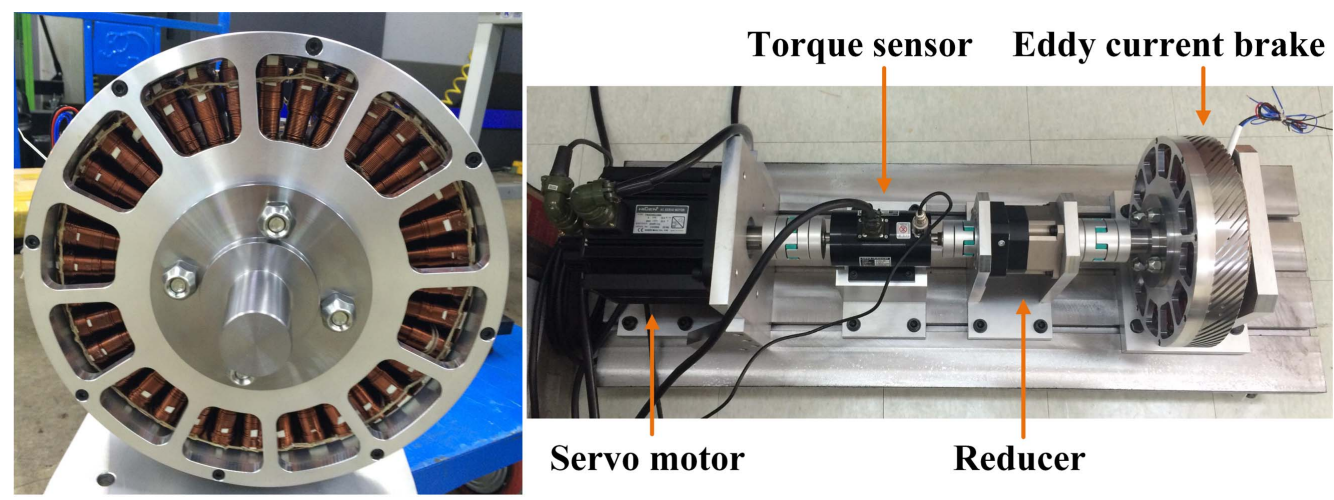

Servo motor

Reducer

Fig. 13. (Color online) Production model and the overall system structure. 


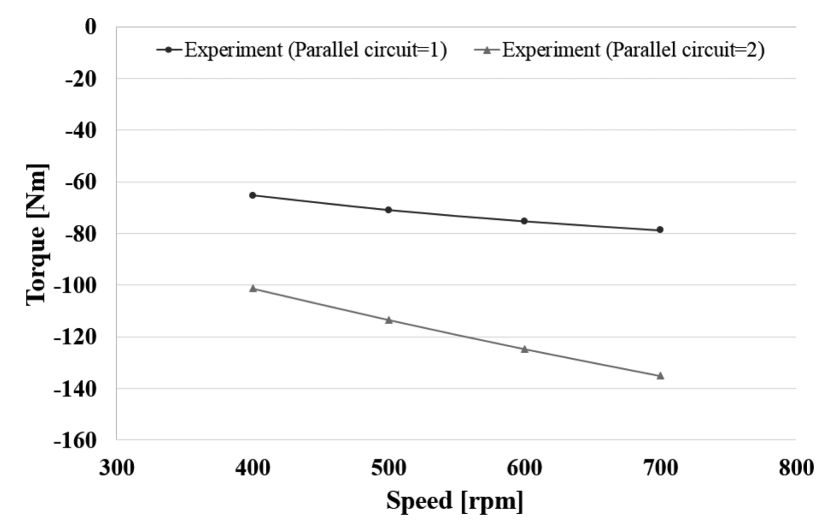

Fig. 15. Experiment result of the eddy current brake.

current path and end turns between the 2D and 3D.

\section{Experimental Verification}

The production models and the overall system structure is as follows.

When the eddy current brake is constructed in a way that the parallel circuit is configured as one, there is a change in the torque, input voltage and temperature based on time as shown in Fig. 14.

Through Fig. 14, from the time of starting the eddy current braking, the temperature of the coil is found to be rising. Also, the phenomenon that the torque is reduced according to the braking time can be seen clearly, because the temperature of drum rises in addition to the temperature of the coil.

The experimental results on different number of parallel circuits are shown in Fig. 15. The number of parallel circuits was changed by varying the winding of the circuit.

When the parallel circuit is configured as 1 , the current density becomes twice as large as the current density of the parallel circuit that is configured as 2 . As a result, the rate of temperature rise of the coil and drum becomes large. Therefore, the error between the analysis result of FEA and experiment result is a bit larger. Also, through the winding change, it can be seen that the braking force of the eddy current brake can be improved.

\section{Conclusion}

The eddy current brake presented in this paper can take a high current density because this operates momentarily during braking. Also, this has the advantage of being able to take a higher current density at a low speed than the high speed due to the differences in the heat generated by the braking speed. Therefore, this paper improves the torque at the low speed through the winding change.

\section{Acknowledgment}

This research was supported by Basic Science Research Program through the National Research Foundation of Korea (NRF) funded by the Ministry of Science, ICT \& Future Planning (NRF-2014R1A1A1003334).

This work was supported by the Human Resources Program in Energy Technology of the Korea Institute of Energy Technology Evaluation and Planning (KETEP), granted financial resource from the Ministry of Trade, Industry \& Energy, Republic of Korea. (No. 20154030200900).

\section{References}

[1] L. Jin, X. Jianchang, and L. Fang, Third international conference on measuring technology and mechatronics automation (ICMTMA), 2, 1111 (2011).

[2] M. Hofmann, T. Werle, R. Pfeiffer, and A. Binder, IEEE Trans. Magn. 36, 1758 (2000).

[3] S. E. Gay and M. Ehsani, IEEE Trans. Magn. 42, 319 (2006).

[4] S. Cho, T. Jeong, J. Bae, C. Yoo, and J. Lee, Journal of Electrical Engineering and Technology, 12, 459 (2017).

[5] J.-N. Bae, Y.-E. Kim, Y.-W. Son, H.-S. Moon, C.-H. Yoo, and J. Lee, IEEE Trans. Ind. Electron. 62, 3091 (2014).

[6] R. Yazdanpanah and M. Mirsalim, IEEE Trans. Magn. 50, 8000710 (2014).

[7] A. Zamani, IET Electrical Systems in Transportation, 4, 38-44 (2014).

[8] J. D. Edwards, B. V. Jayawant, W. R. C. Dawson, and D. T. Wright, IEE Proc. Electr. Power Appl. 146, 627 (1999).

[9] S. Sharif, J. Faiz, and K. Sharif, IET Electric Power Applications, 6, 661 (2012). 